\title{
Research and Practice on the Training Mode of Targeted Poverty Alleviation-oriented Practice for College Students
}

\author{
Yu Zhang* \\ Tianjin University of Technology and Education, Tianjin, 300222, China. \\ E-mail: zhangyutzsd@126.com
}

Fund Project: Tianjin Vocational and Technical Normal University Scientific Research Project_—Precise implementation of education for poverty alleviation, research and practice of internship training support for college students (Project No. SK2003); Tianjin Teaching Achievement Award Key Cultivation Project—Research and practice on the construction of vocational and technical teacher education community practice (Project No. PYGJ-034).

Abstract: Taking the research and implementation of the training mode of the students who practice and support teaching as the breakthrough point in the process of implementing the educational poverty alleviation, this paper tries to realize the multi-dimensional objectives and requirements such as poverty alleviation content, objectives, training mode, specific implementation path of poverty alleviation, evaluation, system guarantee, etc. in the process of implementing the educational poverty alleviation work in vocational colleges in Western regions by means of supporting teaching through practice. Construct the educational characteristics of higher education that targeted poverty alleviation and talent training are coordinated and consistent.

Keywords: Education poverty alleviation; Precise; Teaching Practice in Rural Area; Training

\section{Research status}

It is the mission of the times of colleges and universities in the cause of socialist construction to integrate the resources of education for poverty alleviation from multiple sources such as industry, and government, and actively utilize the advantages of higher education to build a precise mechanism for education for poverty alleviation. Selecting outstanding college students to provide internships for poverty alleviation and education is an important way for colleges and universities to serve the targeted poverty alleviation work. In the current research on the problem of supporting education for college students, many scholars have put forward the problems of a single form of supporting education for college students, a short time for supporting education, and difficulty in achieving continuity. Supporting teaching with on-the-job internships can achieve consistency between the support teaching plan and the student training plan to a certain extent, and better solve the above problems. However, the existing research still needs to be further deepened and improved regarding the "precision" problem of supporting education and poverty alleviation through the internship.

Teacher Wendong Liao pointed out that there are obvious outstanding problems in China that the university's training mechanism for supporting college students is not perfect[1]. Zhibin Tang, Mei Hu, and Sumei Tan proposed "focus on vocational education and training, and promote decent employment for sustainable development of the poor"'[2]. Liangui Qu analyzed the problem of targeted poverty alleviation of vocational education, and proposed that "vocational education must play a greater role in targeted poverty alleviation, and it requires the participation of government, vocational colleges, industry enterprises to realize the poverty alleviation targets”[3]. Shulan Liu, Xuezhen

Copyright (C) 2020 Yu Zhang

doi: $10.18282 /$ le.v9i6.1287

This is an open-access article distributed under the terms of the Creative Commons Attribution Non-Commercial License

(http://creativecommons.org/licenses/by-nc/4.0/), which permits unrestricted non-commercial use, distribution, and reproduction in any medium, provided the original work is properly cited. 
Zhang, and Mei Li proposed that "poverty alleviation in higher education must be through the integration of funds, pooling talents and coordinating different departments through the evaluation and assessment system of talents. The linkage mechanism for the poverty alleviation platform and the poverty alleviation security system of colleges and universities and other social practitioners should be optimized"[4].

The methods and strategies put forward by scholars cover various aspects such as the linkage mechanism of relevant stakeholders, evaluation and assessment, and provide useful ideas for the further practice of college students' internship support work. In order to solve the problem of precision, it is necessary to fully consider and analyze the specific needs of assisting regions and institutions, and find out the professional positioning of the selected college students and the differences with actual needs, including professional knowledge and abilities, as well as cognitive differences in the areas of assistance in terms of emotion, culture, and psychological expectations. The training plan based on the current professional talent training goals and the curriculum system, and even the specific education and teaching implementation, it is naturally difficult to take into account the specific needs of all regions. Therefore, in order to solve the problem of accurately implementing education support and poverty alleviation, supplemented by appropriate training is an effective method.

\section{The significance of the research and implementation of the internship training mode for college students}

It supports education and poverty alleviation through internships of college students, and conducts research and practice on the problem of targeted poverty alleviation in vocational education in the western area of education poverty alleviation. It is directly aimed at the targeted poverty alleviation work of higher education, and strives to solve the implementation of educational poverty alleviation in the western vocational colleges, realize multi-dimensional goals and requirements in the work process, and build a school characteristic of precise poverty alleviation. The research and implementation of the work will give full play to the social value of higher education institutions and the advantages of teacher training, especially the unique advantages of vocational and technical normal colleges in implementing vocational education for poverty alleviation. At the same time, it can further enrich the connotation of talent training in vocational and technical normal colleges, further practice the ideas of running colleges and universities from the perspective of education, teaching, and talent training in the front line of poverty alleviation, and deepen the experience and achievements of in-service teacher training.

\section{The specific content of the research and implementation of the internship training model of college students}

3.1 Conduct research on the precise implementation of practical strategies for poverty alleviation through education. On the one hand, the practical strategy is to accurately locate the relationship between universities, local governments, and local industries, as well as the job positioning of various stakeholders, including the coordination of various elements involved in precise poverty alleviation in the school's specific work, the system guarantees of all parties, and specific implementation methods.

3.2 Demand analysis for the precise implementation of vocational education for poverty alleviation in western contiguous areas. It is necessary to investigate and sort out the needs of local government departments and vocational colleges, aiming at the government level, including the status quo of vocational education, local industries, employment trends and changes in demand, etc. For relevant colleges, it is needed to sort out skills training, skill competition guidance, and professional training construction, teacher training, course teaching and other aspects. On the basis of a comprehensive understanding and precise refinement of the needs, they should develop a feasible support model, and draft a demand plan for interns of college students.

3.3 Research on the practice teaching support model aimed at implementing precision education for poverty alleviation in vocational schools in the western regions such as Xinjiang Hotan, including the management model, the specific implementation of supporting teaching work, the study of the learning mechanism, assistance methods, and evaluation mode of the corresponding courses that cannot be carried out in the school during the internship period. 
Combined with the specific implementation of the training work of supporting college students, the training methods and training effects of professional construction ability before and after the training process, teaching research ability, course teaching implementation ability based on the action-oriented concept, class teacher ability, skill level by profession and work type, etc. should be researched.

3.4 The research and practice of the online and offline hybrid training mode of internship support college students with the goal of improving comprehensive literacy, vocational education and teaching ability, and educating ability. These should include the target positioning of training, the feasible training implementation mode, process and specific methods under the situation of epidemic prevention and control, the organization of characteristic training teachers, the development of typical training cases, the difference and consistency research of various training contents, and talents collaborative research on the implementation of training programs, etc.

The specific training content needs to be carried out in accordance with the current status of talent training in colleges and universities, the needs of the matching area, and the professional characteristics of the college students in various majors. It usually needs to include vocational education laws and regulations, education poverty alleviation related preaching, education support work introduction, and support education exchanges in the western region, cultural characteristics introduction, conventional basic teaching skills enhancement, professional course teaching skills enhancement, etc. In addition, full consideration should be given to the use of teaching language, the enhancement of action-oriented teaching skills, the enhancement of professional construction capabilities, the development of courses, the construction of internship training bases, the development of training projects, the organization of subject competitions and competition guidance, etc. The content that the school urgently needs and is conducive to better achieving sustainable development.

\section{Conclusion}

The author's school, Tianjin Vocational and Technical Normal University, has distinctive characteristics and strong social service functions. It can provide a variety of specific methods for the implementation of targeted poverty alleviation. According to the Tianjin High-quality Promoting East-West Poverty Alleviation Cooperation and Support Cooperation, and Helping to Complete the Poverty Alleviation Task on Schedule in 2020 (Tianjin Party Hall [2020] No. 12), Tianjin Vocational and Technical Normal University attaches great importance to the poverty alleviation cause and values practical behaviors of poverty alleviation, study the internal ideological constraints, psychological weaknesses, external material scarcity, lack of ability and other problems of the assistance objects in poverty-stricken areas, analyze the needs and priorities of the assistance areas and institutions, and implement targeted and precise internships. The training work of supporting college students has gradually formed a model of the work plan for implementing precision education poverty alleviation through internships, which can provide a certain reference for other fraternal colleges and universities to implement precision education poverty alleviation.

\section{References}

1. Liao W. Analysis of the problems and countermeasures of supporting education for college students. Record Education 2017; (07): 120-131.

2. Tang Z, Hu M, Tan S. The international experience of educational poverty alleviation and China's path selection in a comparative perspective. Comparative Education Research 2019; (04): 37-44.

3. Qu L. From vocational education poverty alleviation to vocational education precision poverty alleviation. Adult Education 2018; (11): 75-80.

4. Liu S, Zhang X, Li M. The optimization path of education for poverty alleviation in colleges and universities under the big poverty alleviation pattern. Journal of Fujian Agriculture and Forestry University (Philosophy and Social Sciences Edition) 2019; (22): 1-6. 